\title{
Assessment of Rainfall and Temperature using OSA Estimators of Extreme Value Distributions
}

\author{
N. Vivekanandan, Dr.S.K. Roy and Rahul S. Jagtap
}

\begin{abstract}
Estimation of rainfall and temperature for a desired return period is one of the pre-requisite for planning, design and management of the civil structures at the project site. This paper illustrates the use of extreme value distributions for assessment of rainfall and maximum/ minimum temperature recorded at Bhavnagar and Hissar regions. Order statistics approach is used for determination of parameters of the distributions. Kolmogorov-Smirnov is applied for checking the adequacy of fitting of distributions to the recorded rainfall and temperature data. Diagnostic analysis involving $D$-index is used for selection of a suitable distribution for estimation of annual daily maximum rainfall and annual maximum/ minimum temperature for different return periods. The paper presents that the Gumbel distribution is better suited for assessment of rainfall and temperature for the regions under study.
\end{abstract}

Keywords--- D-index; Frechet; Gumbel; KolmogorovSmirnov; Rainfall; Temperature

\section{INTRODUCTION}

$\mathrm{T}$ ECHNICAL and engineering appraisal of large infrastructure projects such as nuclear/ hydro/ thermal power plants, dams, flood defence, coastal control measures and airports needs to be carried out during the planning and formulation stages of such projects. In a hydrological context, it is well recognised that whatsoever extreme the designloading, more severe conditions are likely to be encountered in nature. For the reason, analysis of recorded rainfall and temperature relating to the geographical region where the project is located is a basic requirement for assessing such phenomena, and arriving at structural and other related design parameters for the project [1]. Depending on the size and design life of the structure involved, the different return periods for which the identified design criteria are generally stipulated. In practice, the expected extreme event for 1000year (yr) return period is often used to arrive at a design parameter that a structure must withstand during its lifetime [2].

In probabilistic theory, generalized extreme value distribution is identified as a family of continuous probability

N. Vivekanandan, Assistant Research Officer, Central Water and Power Research Station, Pune, Maharashtra, E-mail: anandaan@rediffmail.com

Dr.S.K. Roy, Chief Research Officer, Central Water and Power Research Station, Pune, Maharashtra.

Rahul S. Jagtap, Joint Director, National Sample Survey Organization, Nagpur, Maharashtra.

DOI: 10.9756/BIJSESC.10032 distributions that include Gumbel, Frechet and Weibull [3]. Research studies detailed that the extreme value distributions are widely applied for assessment of meteorological variables such as rainfall, evaporation, temperature and wind speed, etc; and therefore adopted in the present study [4-6]. Standard procedures like Method of Moments (MOM), Probability Weighted Moments (PWM), Maximum Likelihood Method (MLM), Method of Least Squares (MLS) and Lieblein technique based on Order Statistics Approach (OSA) are commonly available for determination of parameters of extreme value distributions. Ranyal and Salas [7] analyzed that MOM estimates are usually inferior in quality because higher order moments are more likely to be highly biased in relative small samples. Phien [8] studied that MLM is considered the most efficient method, since it provides the smallest sampling variance of the estimated parameters and hence of the estimated quantiles compared to other methods. He also studied that the method has the disadvantage of frequently giving biased estimates and often failed to give the desired accuracy in estimating extremes from hydrological data. Landwehr et al [9] discussed that MLM may produce quality estimators in small samples, especially when the random variable is restricted to an interval that depends on the parameters. Rasmussen and Gautam [10] described that the parameter estimates from small samples using MLS and PWM are sometimes more accurate than the MLM estimates and less than the OSA estimates for Gumbel distribution. In view of the above, Lieblein [11] suggested OSA for estimation of parameters of Gumbel and Frechet distributions for modelling meteorological data. He also described that the OSA estimators are unbiased and having minimum variance.

Arora and Singh [12] applied five parameter estimation methods of Gumbel distributions to different river basins of USA and concluded that PWM is better method for modelling of flood data when interpolation is involved for higher order return periods. Manik and Datta [13] made an attempt to compare the MOM, MLM, PWM and OSA estimators of Gumbel and analysed that PWM is the best suited for estimation of water level at Digha site. Celik [14] applied the distributional parameters in assessing the suitable probability distribution for modelling wind speed data. Vivekanandan et al [15] applied OSA of Gumbel and Frechet distributions for estimation of 3-seconds average maximum wind speed for different return periods for Visakhapatnam region.

In this paper, OSA used for determination of estimators of Gumbel and Frechet distributions for assessment of rainfall and temperature for Bhavnagar and Hissar regions in accordance with AERB guidelines. Weibull is not considered in the present study because of non-existence of OSA for 
determination of parameters of the distribution. KolmogorovSmirnov (KS) test is applied for checking the adequacy of fitting of the distributions to the recorded rainfall and temperature data. Diagnostic analysis involving D-index is used for selection of a suitable distribution for estimation of Annual Daily Maximum Rainfall (ADMR) and Annual maximum/ minimum Temperature $\left(\mathrm{AT}_{\mathrm{MAX}}\right.$ and $\left.\mathrm{AT}_{\mathrm{MIN}}\right)$ for different return periods for the regions under study. The paper illustrates the procedures adopted in assessment of rainfall and temperature using extreme value distributions, KS test and diagnostic analysis, and the results obtained thereof.

\section{Methodology}

\section{A. Probability Distributional Models}

The Cumulative Distribution Functions (CDFs) of Gumbel and Frechet distributions for the series containing largest and smallest values are given in Table 1.

Table 1: CDFs of Gumbel and Frechet Distributions

\begin{tabular}{|l|c|c|}
\hline \multirow{2}{*}{ Distribution } & \multicolumn{2}{|c|}{ CDFs for the series containing } \\
\cline { 2 - 3 } & Largest values & Smallest values \\
\hline Gumbel & $\mathrm{F}(\mathrm{X})=\mathrm{e}^{-\mathrm{e}^{-\left(-\frac{\mathrm{x}_{\mathrm{G}}-\alpha_{\mathrm{G}}}{\beta_{\mathrm{G}}}\right)}}$ & $\mathrm{F}(\mathrm{X})=1-\mathrm{e}^{-\mathrm{e}^{-\left(\frac{\mathrm{X}_{\mathrm{G}}-\alpha_{\mathrm{G}}}{\beta_{\mathrm{G}}}\right)}}$ \\
\hline Frechet & $\mathrm{F}(\mathrm{X})=\mathrm{e}^{-\left(\frac{\mathrm{X}_{\mathrm{F}}}{\beta_{\mathrm{F}}}\right)^{\left(-\lambda_{\mathrm{F}}\right)}}$ & $\mathrm{F}(\mathrm{X})=1-\mathrm{e}^{-\left(\frac{\mathrm{X}_{\mathrm{F}}}{\beta_{\mathrm{F}}}\right)^{\left(-\lambda_{\mathrm{F}}\right)}}$ \\
\hline
\end{tabular}

Here $\alpha_{\mathrm{G}}$ and $\beta_{\mathrm{G}}$ are the location and scale parameters of Gumbel distribution. The values of expected events $\left(\mathrm{X}_{\mathrm{G}}\right)$ for different MRIs (T) are computed from $\mathrm{X}_{\mathrm{G}}=\alpha_{\mathrm{G}}+\mathrm{Y}_{\mathrm{T}} \beta_{\mathrm{G}}$ with $\mathrm{Y}_{\mathrm{T}}=-\ln \left(-\ln (1-(1 / \mathrm{T}))\right.$. Likewise, $\beta_{\mathrm{F}}$ and $\lambda_{\mathrm{F}}$ are the scale and shape parameters of Frechet distribution. Based on extreme value theory, Frechet distribution can be transformed to Gumbel distribution through logarithmic transformation using natural logarithm of the actual variable. Under this transformation, the expected events $\left(\mathrm{X}_{\mathrm{F}}\right)$ for different MRIs can be computed from $\mathrm{X}_{\mathrm{F}}=\operatorname{Exp}\left(\mathrm{X}_{\mathrm{G}}\right), \beta_{\mathrm{F}}=\operatorname{Exp}\left(\alpha_{\mathrm{G}}\right)$ and $\lambda_{\mathrm{F}}=1 / \beta_{\mathrm{G}}$ [16].

\section{A1. Order Statistics Approach}

The approach is based on the assumption that the set of extreme values constitutes a statistically independent series of observations. The OSA estimators of Gumbel distribution are given by:

$$
\alpha_{\mathrm{G}}=\mathrm{r}^{*} \alpha_{\mathrm{M}}^{*}+\mathrm{r}^{\prime} \alpha_{\mathrm{M}}^{\prime} \text { and } \beta_{\mathrm{G}}=\mathrm{r}^{*} \beta_{\mathrm{M}}^{*}+\mathrm{r}^{\prime} \beta_{\mathrm{M}}^{\prime}
$$

where $r^{*}$ and $r^{\prime}$ are proportionality factors, which can be obtained from the selected values of $\mathrm{k}, \mathrm{n}$ and $\mathrm{n}^{\prime}$ using the relations $r^{*}=k n / N$ and $r^{\prime}=n^{\prime} / N$. Here, $N$ is the sample size contains basic data that are divided into $\mathrm{k}$ sub groups of $\mathrm{n}$ elements each leaving $n^{\prime}$ remainders. In OSA, $\alpha_{M}^{*}$ and $\beta_{M}^{*}$ are the distribution parameters of the groups and $\alpha_{M}^{\prime}$ and $\beta_{\mathrm{M}}^{\prime}$ are the parameters of the remainders, if any. These can be computed from the following equations:

$$
\begin{aligned}
& \alpha_{M}^{*}=(1 / \mathrm{k}) \sum_{\mathrm{i}=1}^{\mathrm{n}} \alpha_{\mathrm{ni}} \mathrm{S}_{\mathrm{i}} \text { and } \alpha_{\mathrm{M}}^{\prime}=\sum_{\mathrm{i}=1}^{\mathrm{n}^{\prime}} \alpha_{\mathrm{ni}} \mathrm{X}_{\mathrm{i}} \\
& \beta_{\mathrm{M}}^{*}=(1 / \mathrm{k}) \sum_{\mathrm{i}=1}^{\mathrm{n}} \beta_{\mathrm{ni}} \mathrm{S}_{\mathrm{i}} \text { and } \beta_{\mathrm{M}}^{\prime}=\sum_{\mathrm{i}=1}^{\mathrm{n}^{\prime}} \beta_{\mathrm{n}^{\prime} \mathrm{i}} \mathrm{X}_{\mathrm{i}}
\end{aligned}
$$

where $S_{i}=\sum_{i=1}^{k} X_{i j}, j=1,2,3, . ., n$. Table 2 gives the weights of

$\alpha_{\mathrm{ni}}$ and $\beta_{\mathrm{ni}}$ for computation of OSA estimators [17].

Table 2: Weights $\alpha_{\mathrm{ni}}$ and $\beta_{\mathrm{ni}}$ for Computation of OSA

\begin{tabular}{|c|c|c|c|c|c|c|}
\multicolumn{7}{|c|}{ Estimators } \\
\hline$\alpha_{\text {ni }} /$ & \multicolumn{7}{|c|}{$\mathrm{i}$} & \multicolumn{1}{c|}{ ( } \\
$\beta_{\text {ni }}$ & 1 & 2 & 3 & 4 & 5 & 6 \\
\hline$\alpha_{2 \mathrm{i}}$ & 0.9164 & 0.0836 & & & & \\
\hline$\alpha_{3 \mathrm{i}}$ & 0.6563 & 0.2557 & 0.0880 & & & \\
\hline$\alpha_{4 \mathrm{i}}$ & 0.5109 & 0.2639 & 0.1537 & 0.0714 & & \\
\hline$\alpha_{5 \mathrm{i}}$ & 0.4189 & 0.2463 & 0.1676 & 0.1088 & 0.0584 & \\
\hline$\alpha_{6 \mathrm{i}}$ & 0.3555 & 0.2255 & 0.1656 & 0.1211 & 0.0835 & 0.0489 \\
\hline$\beta_{2 \mathrm{i}}$ & -0.7214 & 0.7214 & & & & \\
\hline$\beta_{3 \mathrm{i}}$ & -0.6305 & 0.2558 & 0.3747 & & & \\
\hline$\beta_{4 \mathrm{i}}$ & -0.5586 & 0.0859 & 0.2239 & 0.2488 & & \\
\hline$\beta_{5 \mathrm{i}}$ & -0.5031 & 0.0065 & 0.1305 & 0.1817 & 0.1845 & \\
\hline$\beta_{6 \mathrm{i}}$ & -0.4593 & -0.0359 & 0.0732 & 0.1267 & 0.1495 & 0.1458 \\
\hline
\end{tabular}

The OSA estimators are used to estimate the expected rainfall/ temperature for different return periods. The Standard Error (SE) on the estimated value is computed by:

$$
\begin{aligned}
& \mathrm{SE}=\left[\operatorname{Var}\left(\mathrm{X}_{\mathrm{T}}\right)\right]^{1 / 2}, \operatorname{Var}\left(\mathrm{X}_{\mathrm{T}}\right)=\mathrm{r}^{*} \mathrm{X}_{\mathrm{n}}+\mathrm{r}^{\prime} \mathrm{X}_{\mathrm{n}^{\prime}} \\
& \mathrm{r}^{*}=\frac{1}{\mathrm{k}}\left(\frac{\mathrm{kn}}{\mathrm{N}}\right)^{2} \text { and } \mathrm{r}^{\prime}=\left(\frac{\mathrm{n}^{\prime}}{\mathrm{N}}\right)^{2}
\end{aligned}
$$

$X_{n}$ and $X_{n^{\prime}}$ are defined by the general form as $X_{n}=\left(A_{n} Y_{T}^{2}+B_{n} Y_{T}+C_{n}\right) \beta_{G}^{2}$. Table 3 gives the values of $A_{n}, B_{n}$, and $C_{n}$ used in estimation of SE for the expected extreme events [17]. The lower and upper confidence limits (LCL and UCL) at 95\% level for the estimated values are computed from $\mathrm{LCL}=\mathrm{X}_{\mathrm{T}}-1.96 \mathrm{SE}$ and $\mathrm{UCL}=\mathrm{X}_{\mathrm{T}}+1.96 \mathrm{SE}$.

Table 3: Variance Determinators for $\mathrm{X}_{\mathrm{n}}$

\begin{tabular}{|c|c|c|c|}
\hline $\mathrm{n}$ & $\mathrm{A}_{\mathrm{n}}$ & $\mathrm{B}_{\mathrm{n}}$ & $\mathrm{C}_{\mathrm{n}}$ \\
\hline 2 & 0.71186 & -0.12864 & 0.65955 \\
\hline 3 & 0.34472 & 0.04954 & 0.40286 \\
\hline 4 & 0.22528 & 0.06938 & 0.29346 \\
\hline 5 & 0.16665 & 0.06798 & 0.23140 \\
\hline 6 & 0.13196 & 0.06275 & 0.19117 \\
\hline
\end{tabular}

\section{B. Kolmogorov-Smirnov Test}

The KS statistics is defined by:

$$
\mathrm{KS}=\underset{\mathrm{i}=1}{\mathrm{Nax}}\left(\mathrm{F}_{\mathrm{e}}\left(\mathrm{X}_{\mathrm{i}}\right)-\mathrm{F}_{\mathrm{D}}\left(\mathrm{X}_{\mathrm{i}}\right)\right)
$$

Here $F_{e}\left(X_{i}\right)=(i-0.35) / N$ is the empirical CDF of $X_{i}$ and $F_{D}\left(X_{i}\right)$ is the computed CDF of $X_{i}$ by Gumbel and Frechet distributions

If the computed value of KS statistics given by the distribution is less than that of theoretical value at the desired significance level then the particular distribution is accepted to be adequate than any other distribution for assessment of rainfall and temperature [18]. 


\section{Diagnostic Test}

The D-index statistics is defined by:

$$
\text { D-index }=\frac{1}{\bar{X}} \sum_{i=1}^{6}\left|X_{i}-X_{i}^{*}\right|
$$

where, $X_{i}$ and $X_{i}^{*}$ are the $i^{\text {th }}$ highest recorded and estimated rainfall/ temperature using Gumbel and Frechet distributions, and $\overline{\mathrm{X}}$ is the average recorded rainfall/ temperature. The distribution having the least value for Dindex is considered as the best distribution for assessment of rainfall and temperature [19].

\section{APPLICATION}

An attempt has been made to assess the expected extreme rainfall and maximum/ minimum temperature for different return periods for Bhavnagar and Hissar regions. The series of $\mathrm{ADMR}, \mathrm{AT}_{\mathrm{MAX}}$ and $\mathrm{AT}_{\mathrm{MIN}}$ derived from daily rainfall and temperature data, and further used to estimate the values of $\mathrm{ADMR}, \mathrm{AT}_{\mathrm{MAX}}$ and $\mathrm{AT}_{\mathrm{MIN}}$ for different return periods using OSA estimators of Gumbel and Frechet distributions for Bhavnagar and Hissar regions. Rainfall and temperature data recorded at Bhavnagar for the period 1969-2006 and Hissar for the period 1969-2007 are used [20]. Table 4 gives the statistical parameters of the recorded $\mathrm{ADMR}, \mathrm{AT}_{\mathrm{MAX}}$ and $\mathrm{AT}_{\mathrm{MIN}}$ for Bhavnagar and Hissar.

Table 4: Statistical Parameters of Recorded ADMR, $\mathrm{AT}_{\mathrm{MAX}}$ and $\mathrm{AT}_{\mathrm{MIN}}$ for Bhavnagar and Hissar

\begin{tabular}{|l|c|c|c|c|c|c|}
\hline \multirow{2}{*}{ Statistical parameters } & \multicolumn{3}{|c|}{ Bhavnagar } & \multicolumn{3}{c|}{ Hissar } \\
\cline { 2 - 7 } & $\mathrm{ADMR}$ & $\mathrm{AT}_{\mathrm{MAX}}$ & $\mathrm{AT}_{\mathrm{MIN}}$ & $\mathrm{ADMR}$ & $\mathrm{AT}_{\mathrm{MAX}}$ & $\mathrm{AT}_{\mathrm{MIN}}$ \\
\hline Mean & $114.1 \mathrm{~mm}$ & $44.0^{\circ} \mathrm{C}$ & $8.5^{\circ} \mathrm{C}$ & $94.8 \mathrm{~mm}$ & $46.5^{\circ} \mathrm{C}$ & $2.5^{\circ} \mathrm{C}$ \\
\hline Standard deviation & $79.8 \mathrm{~mm}$ & $1.2^{\circ} \mathrm{C}$ & $1.8^{\circ} \mathrm{C}$ & $59.1 \mathrm{~mm}$ & $1.4^{\circ} \mathrm{C}$ & $1.6^{\circ} \mathrm{C}$ \\
\hline Skewness & 2.216 & 0.846 & 0.151 & 1.520 & -0.452 & -0.821 \\
\hline Kurtosis & 5.836 & 1.487 & -0.581 & 1.779 & 0.541 & 0.586 \\
\hline
\end{tabular}

\section{RESULTS AND DISCUSSIONS}

A. Estimation of $A D M R, A T_{M A X}$ and $A T_{M I N}$ using Extreme Value Distributions

By applying the procedures described above, a computer program was developed and used to estimate the expected extreme rainfall and maximum/ minimum temperature for Bhavnagar and Hissar. Tables 5 and 6 give the estimates of $\mathrm{ADMR}, \mathrm{AT}_{\mathrm{MAX}}$ and $\mathrm{AT}_{\mathrm{MIN}}$ together with $\mathrm{SE}$ for different return periods using OSA estimators of Gumbel and Frechet distributions for Bhavnagar and Hissar.

Table 5: Estimates of ADMR with Standard Error for Different Return Periods Using OSA Estimators of Gumbel and Frechet Distributions; Bhavnagar

\begin{tabular}{|c|c|c|c|c|c|c|c|c|c|c|}
\hline \multirow{3}{*}{$\begin{array}{c}\text { Return } \\
\text { period } \\
(\mathrm{yr})\end{array}$} & \multicolumn{4}{|c|}{$\operatorname{ADMR}(\mathrm{mm})$} & \multicolumn{4}{|c|}{$\mathrm{AT}_{\text {MAX }}\left({ }^{\circ} \mathrm{C}\right)$} & \multirow{2}{*}{\multicolumn{2}{|c|}{$\frac{\mathrm{AT}_{\mathrm{MIN}}\left({ }^{\circ} \mathrm{C}\right)}{\text { Gumbel }}$}} \\
\hline & \multicolumn{2}{|c|}{ Gumbel } & \multicolumn{2}{|c|}{ Frechet } & \multicolumn{2}{|c|}{ Gumbel } & \multicolumn{2}{|c|}{ Frechet } & & \\
\hline & ER & $\mathrm{SE}$ & ER & SE & ET & SE & ET & SE & ET & SE \\
\hline 2 & 97.8 & 9.5 & 83.6 & 8.4 & 43.6 & 0.3 & 43.6 & 0.3 & 9.7 & 0.6 \\
\hline 5 & 153.5 & 15.3 & 146.5 & 24.4 & 45.0 & 0.4 & 45.1 & 0.4 & 6.0 & 1.0 \\
\hline 10 & 190.4 & 20.2 & 212.6 & 48.0 & 46.0 & 0.5 & 46.1 & 0.6 & 3.5 & 1.3 \\
\hline 20 & 225.7 & 25.2 & 303.7 & 87.8 & 46.9 & 0.7 & 47.1 & 0.7 & 1.1 & 1.7 \\
\hline 50 & 271.5 & 31.8 & 482.1 & 182.6 & 48.1 & 0.8 & 48.4 & 0.9 & -1.9 & 2.1 \\
\hline 100 & 305.8 & 36.9 & 681.4 & 307.6 & 49.0 & 1.0 & 49.4 & 1.1 & -4.2 & 2.5 \\
\hline 200 & 340.0 & 42.0 & 962.1 & 507.9 & 49.9 & 1.1 & 50.5 & 1.3 & -6.5 & 2.8 \\
\hline 500 & 385.0 & 48.8 & 1516.4 & 964.4 & 51.0 & 1.3 & 51.9 & 1.6 & -9.5 & 3.3 \\
\hline 1000 & 419.0 & 53.9 & 2138.6 & 1546.3 & 51.9 & 1.4 & 53.0 & 1.8 & -11.8 & 3.6 \\
\hline
\end{tabular}

From Tables 5 and 6, it may be noted that the estimated ADMR using Frechet distribution is relatively higher than the corresponding values of Gumbel for return periods above 5-yr for Bhavnagar and Hissar. Similarly, from Tables 5 and 6, it may be noted that the estimated $\mathrm{AT}_{\mathrm{MAX}}$ using Frechet distribution is marginally higher than the corresponding values of Gumbel distribution for return periods above 100yr. 
Table 6: Estimates of ADMR with Standard Error for Different Return Periods Using OSA Estimators of Gumbel and Frechet Distributions; Hissar

\begin{tabular}{|c|c|c|c|c|c|c|c|c|c|c|}
\hline \multirow{3}{*}{$\begin{array}{l}\text { Return } \\
\text { period } \\
\text { (yr) }\end{array}$} & \multicolumn{4}{|c|}{ ADMR (mm) } & \multicolumn{4}{|c|}{$\mathrm{AT}_{\mathrm{MAX}}\left({ }^{\circ} \mathrm{C}\right)$} & \multirow{2}{*}{\multicolumn{2}{|c|}{$\frac{\mathrm{AT}_{\mathrm{MIN}}\left({ }^{\circ} \mathrm{C}\right)}{\text { Gumbel }}$}} \\
\hline & \multicolumn{2}{|c|}{ Gumbel } & \multicolumn{2}{|c|}{ Frechet } & \multicolumn{2}{|c|}{ Gumbel } & \multicolumn{2}{|c|}{ Frechet } & & \\
\hline & ER & SE & ER & SE & ET & $\mathrm{SE}$ & ET & $\mathrm{SE}$ & ET & $\mathrm{SE}$ \\
\hline 2 & 85.6 & 8.0 & 74.0 & 7.8 & 46.3 & 0.2 & 46.3 & 0.2 & 2.7 & 0.2 \\
\hline 5 & 133.6 & 12.8 & 135.0 & 23.5 & 47.5 & 0.3 & 47.5 & 0.3 & 1.5 & 0.3 \\
\hline 10 & 165.4 & 16.8 & 201.1 & 47.3 & 48.3 & 0.4 & 48.3 & 0.4 & 0.7 & 0.4 \\
\hline 20 & 195.9 & 21.0 & 294.7 & 88.6 & 49.0 & 0.5 & 49.1 & 0.6 & 0.0 & 0.5 \\
\hline 50 & 235.3 & 26.5 & 483.2 & 190.2 & 50.0 & 0.7 & 50.1 & 0.7 & -1.0 & 0.7 \\
\hline 100 & 264.9 & 30.7 & 700.0 & 328.3 & 50.7 & 0.8 & 50.9 & 0.8 & -1.7 & 0.8 \\
\hline 200 & 294.4 & 34.9 & 1012.7 & 555.8 & 51.4 & 0.9 & 51.8 & 1.0 & -2.5 & 0.9 \\
\hline 500 & 333.2 & 40.5 & 1648.4 & $1,090.3$ & 52.4 & 1.0 & 52.8 & 1.2 & -3.4 & 1.0 \\
\hline 1000 & 362.6 & 44.8 & 2382.1 & $1,792.2$ & 53.1 & 1.1 & 53.7 & 1.3 & -4.2 & 1.1 \\
\hline
\end{tabular}

\section{B. Analysis Based on KS Test}

The values of KS statistics for the series of ADMR, $\mathrm{AT}_{\mathrm{MAX}}$ and $\mathrm{AT}_{\mathrm{MIN}}$ using OSA estimators of Gumbel and Frechet distributions were computed from Eq. (6) and given in Table 7.

Table 7: Computed Values of KS Statistics Using OSA Estimators of Gumbel and Frechet Distributions

\begin{tabular}{|l|c|c|c|c|}
\hline \multirow{2}{*}{$\begin{array}{c}\text { Data } \\
\text { series }\end{array}$} & \multicolumn{3}{|c|}{ Computed values of KS statistics for } \\
\cline { 2 - 5 } & \multicolumn{2}{|c|}{ Bhavnagar } & \multicolumn{2}{c|}{ Hissar } \\
\cline { 2 - 5 } & Gumbel & Frechet & Gumbel & Frechet \\
\hline ADMR & 0.137 & 0.159 & 0.132 & 0.151 \\
\hline $\mathrm{AT}_{\text {MAX }}$ & 0.204 & 0.205 & 0.126 & 0.129 \\
\hline $\mathrm{AT}_{\text {MIN }}$ & 0.545 & $\mathrm{NF}$ & 0.333 & $\mathrm{NF}$ \\
\hline NF: Weibull distribution is not feasible for modelling $\mathrm{AT}_{\text {MIN }}$ \\
\hline \multicolumn{5}{|l}{}
\end{tabular}

From Table 7, it may be noted that the computed values of KS statistics given by Gumbel and Frechet distributions are less than the theoretical values $\left(\mathrm{KS}_{38,0.05}=0.221 ; \mathrm{KS}_{39,0.05}\right.$ $=0.218)$ at $5 \%$ level of significance, and at this level, both distributions are acceptable for assessment of rainfall and temperature of Bhavnagar and Hissar.

\section{Diagnostic Analysis}

In addition to KS test, D-index for the series of ADMR, $\mathrm{AT}_{\mathrm{MAX}}$ and $\mathrm{AT}_{\mathrm{MIN}}$ using OSA estimators of Gumbel and Frechet distributions were computed from Eq. (7) and given in Table 8.
Table 8: Indices of D-index Using OSA Estimators of Gumbel and Frechet distributions

\begin{tabular}{|c|c|c|c|c|}
\hline \multirow{2}{*}{$\begin{array}{c}\text { Data } \\
\text { series }\end{array}$} & \multicolumn{3}{|c|}{ Indices of D-index for } \\
\cline { 2 - 5 } & \multicolumn{2}{|c|}{ Bhavnagar } & \multicolumn{2}{c|}{ Hissar } \\
\cline { 2 - 5 } & Gumbel & Frechet & Gumbel & Frechet \\
\hline $\mathrm{ADMR}$ & 0.041 & 0.432 & 2.334 & 2.770 \\
\hline $\mathrm{AT}_{\text {MAX }}$ & 0.100 & 0.112 & 0.033 & 0.038 \\
\hline $\mathrm{AT}_{\text {MIN }}$ & 5.410 & NF & 3.221 & NF \\
\hline
\end{tabular}

From Table 8, it may be noted that the indices of D-index for the series of $\mathrm{ADMR}$ and $\mathrm{AT}_{\mathrm{MAX}}$ using Gumbel distribution are minimum when compared with the corresponding indices given by Frechet for Bhavnagar and Hissar. Also, from Table 8, it may be noted that the value of $\mathrm{D}$-index for the series containing $\mathrm{AT}_{\mathrm{MIN}}$ is computed as 5.410 for Bhavnagar and 3.221 for Hissar; and are not comparable with the corresponding value of Frechet because of its nonfeasibility of fitting to the recorded $\mathrm{AT}_{\mathrm{MIN}}$. From the results of $\mathrm{KS}$ test and diagnostic analysis, it is suggested that the Gumbel distribution is found to be suitable for estimation of $\mathrm{ADMR}, \mathrm{AT}_{\mathrm{MAX}}$ and $\mathrm{AT}_{\mathrm{MIN}}$ for different return periods for the regions under study. Figures 1-3 show the plots of recorded and estimated $\mathrm{ADMR}, \mathrm{AT}_{\mathrm{MAX}}$ and $\mathrm{AT}_{\mathrm{MIN}}$ given by Gumbel distribution together with confidence limits at $95 \%$ level for Bhavnagar and Hissar.
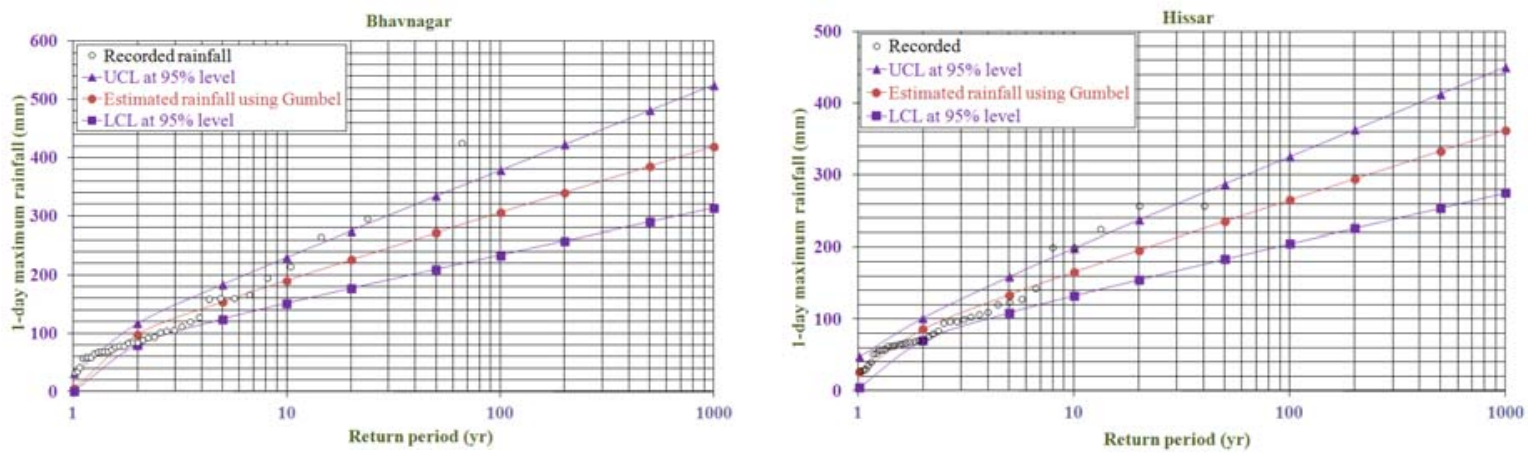

Figure 1: Plot of Recorded and Estimated ADMR for Different Return Periods Using Gumbel Distribution together with 95\% Confidence Limits for Bhavnagar and Hissar 

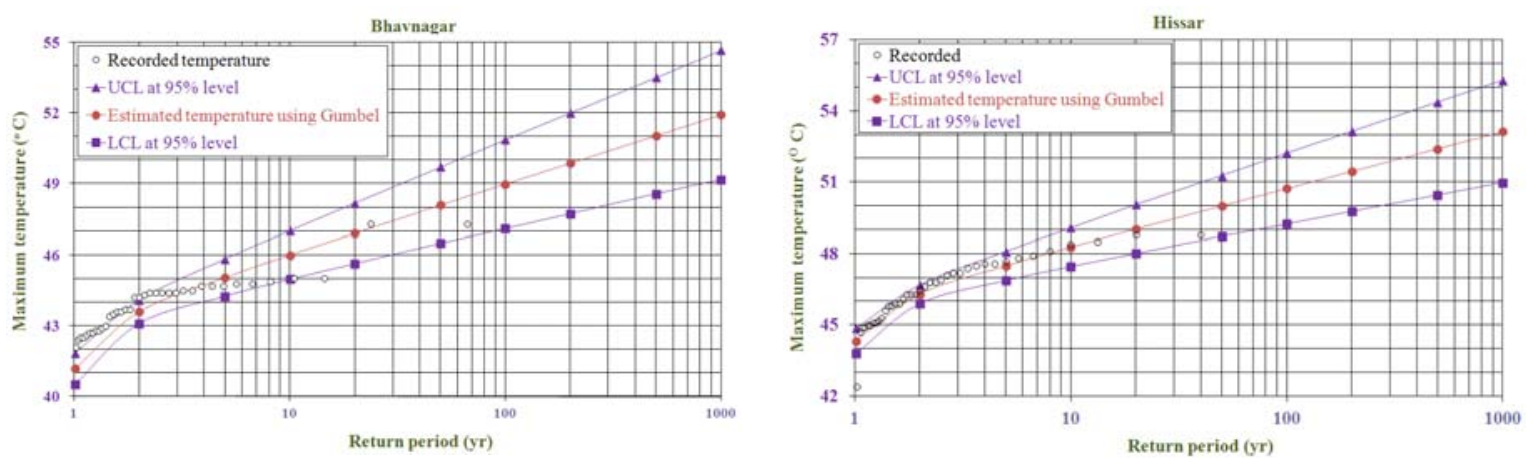

Figure 2: Plot of Recorded and Estimated $\mathrm{AT}_{\mathrm{MAX}}$ for Different Return Periods Using Gumbel Distribution together with 95\% Confidence Limits for Bhavnagar and Hissar
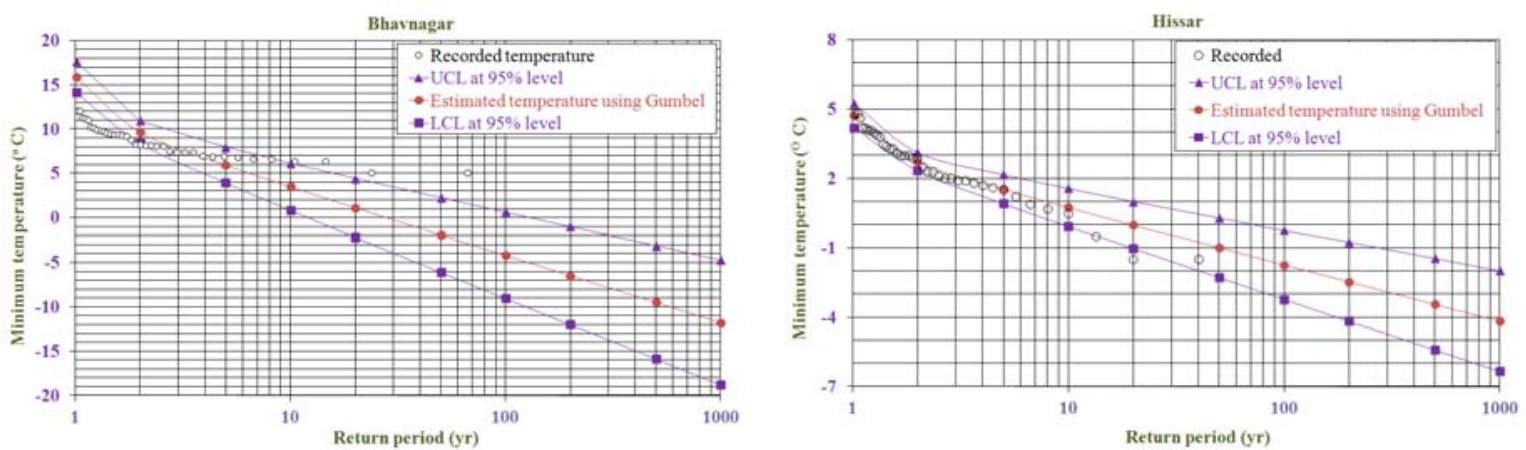

Figure 3: Plot of Recorded and Estimated $\mathrm{AT}_{\mathrm{MIN}}$ for Different Return Periods using Gumbel Distribution together with 95\% Confidence Limits for Bhavnagar and Hissar

From the analysis of results, it is suggested that the 1000 yr return period $\mathrm{ADMR}, \mathrm{AT}_{\mathrm{MAX}}$ and $\mathrm{AT}_{\mathrm{MIN}}$ given by Gumbel distribution such as $419 \mathrm{~mm}, 51.9^{\circ} \mathrm{C}$ and $-11.8^{\circ} \mathrm{C}$ for Bhavnagar; and $362.6 \mathrm{~mm}, 53.1^{\circ} \mathrm{C}$ and $-4.2^{\circ} \mathrm{C}$ for Hissar, may be adopted for design purposes at the regions.

\section{CONCLUSIONS}

The paper presented a study on assessment of rainfall and temperature using OSA estimators of Gumbel and Frechet distributions for Bhavnagar and Hissar. The results of KS tests and diagnostic analysis confirmed that the Gumbel distribution is better suited for estimation of ADMR, $\mathrm{AT}_{\mathrm{MAX}}$ and $\mathrm{AT}_{\mathrm{MIN}}$ for different return periods for the regions under study. The study showed that the estimated 1000 -yr return period $\mathrm{ADMR}, \mathrm{AT}_{\mathrm{MAX}}$ and $\mathrm{AT}_{\mathrm{MIN}}$ given by Gumbel distribution for Bhavnagar are $419 \mathrm{~mm}, 51.9^{\circ} \mathrm{C}$ and $-11.8^{\circ} \mathrm{C}$ respectively. The study also showed that the estimated 1000 yr return period $\mathrm{ADMR}, \mathrm{AT}_{\mathrm{MAX}}$ and $\mathrm{AT}_{\mathrm{MIN}}$ given by Gumbel for Hissar are $362.6 \mathrm{~mm}, 53.1^{\circ} \mathrm{C}$ and $-4.2^{\circ} \mathrm{C}$ respectively. The study presented that these values could be used as input to flood studies for designing drainage system as also for deciding safe grade elevation for the plant while designing the civil structures at Bhavnagar and Hissar regions.

\section{ACKNOWLEDGMENTS}

The authors are thankful to the India Meteorological Department, Pune and M/s NPCIL, Mumbai, for making available the rainfall and temperature data. The authors are grateful to the Director, Central Water and Power Research Station, Pune, for providing the research facilities to carry out the study.

\section{REFERENCES}

[1] International Atomic Energy Agency (IAEA), Extreme meteorological events in nuclear power plant siting excluding tropical cyclones (No. 50-SG-S11A), 1981.

[2] IAEA, Meteorological events in site evaluation for nuclear power plants - IAEA Safety Guide, No. Ns-G-3.4, International Atomic Energy Agency, Vienna, 2003.

[3] V.B. Vaidya, B.I. Karande, Pandey Vyas, M.M. Lunagaria and A.M. Shekh, "Rainfall probability analysis for crop planning in Gujarat state, Journal of Agrometeorology", Vol. 10, Nos. 1-2, Pp 183-185, 2008.

[4] W. May, "Variability and extremes of daily rainfall during the Indian summer monsoon in the period 1901-1989", Global and Planetary Change, Vol. 44, Nos. 1-2, Pp 83-105, 2004.

[5] V.N. Sharda and P.K. Das, "Modelling weekly rainfall data for crop planning in a sub-humid climate of India, Agricultural Water Management", Vol. 76, No. 2, Pp 120-138, 2005.

[6] J.H. Lee and J.H. Heo, "Evaluation of estimation methods for rainfall erosivity based on annual precipitation in Korea", Journal of Hydrology, Vol. 409, Nos. 1-2, Pp 30-48, 2011.

[7] J.A. Ranyal, and J.D. Salas, "Estimation procedures for the type-1 extreme value distribution", Journal of Hydrology, Vol. 87, Nos. 3-4, Pp 315-336, 1986.

[8] H.N. Phien, "A review of methods of parameter estimation for the extreme value type-1 distribution, Journal of Hydraulics", Vol. 90, Nos. 3-4, Pp 251-268, 1987.

[9] J.M. Landwehr, N.C. Matalas, and J.R. Wallis, "Probability weighted moments compared with some traditional techniques in estimating Gumbel parameters and quantiles", Water Resources Research, Vol. 15, No. 5, Pp 1055-1064, 1979. 
[10] P.F. Rasmussen and N. Gautam, "Alternative PWM-estimators of the Gumbel distribution", Journal of Hydrology, Vol. 280, Nos. 1-4, Pp 265-271, 2003.

[11] J. Lieblein, Note on simplified estimates for Type I extreme value distribution, NBSIR 75-647, National Bureau of Standards, U.S. Department of Commerce, Washington D.C, 1974.

[12] K. Arora and V. P. Singh, "On statistical intercomparison of EVI estimators by Monte Carlo simulation, Advances in Water Resources", Vol. 10, No. 2, Pp 87-107, 1987.

[13] D. Manik and S.K. Datta, "A comparative study of estimation of extreme value", Journal of River Behaviour \& Control, Vol. 25, No. 1, Pp 41-47, 1998.

[14] A.N. Celik, "On the distributional parameters used in assessment of the suitability of wind speed probability density functions", Energy Conversion and Management, Vol. 45, Nos. 11-12, Pp 1735-1747, 2004.

[15] N. Vivekanandan, F.T. Mathew and Dr. S.K. Roy, "Modelling of wind speed data using probabilistic approach", Journal of Power and River Valley Development, Vol. 62, Nos. 3-4, Pp 42-45, 2012.

[16] E.J. Gumbel, Statistic of Extremes, $2^{\text {nd }}$ Edition, Columbia University Press, New York, USA, 1960.

[17] Atomic Energy Regulatory Board (AERB), Extreme values of meteorological parameters (Guide No. NF/SG/ S-3), 2008.

[18] J. Zhang, "Powerful goodness-of-fit tests based on the likelihood ratio", Journal of Royal Statistical Society Series-B, Vol. 64, No. 2, Pp 281-294, 2002.

[19] United States Water Resources Council (USWRC), Guidelines for determining flood flow frequency, Bulletin No.17B, Pp 15-19, 1981.

[20] India Meteorological Department (IMD), Report on availability of meteorological data, 2010. 